\title{
Organisational trust: the keystone to patient safety
}

\author{
J Firth-Cozens
}

Qual Saf Health Care 2004;13:56-61. doi: 10.1136/qshc.2003.007971

Trust is an essential part of health care-not only between clinicians and patients but also between staff and management. Research shows us that trust has a beneficial impact on many aspects of working life, including job satisfaction and organisational effectiveness, and both these factors have been shown to affect the quality of patient care. In addition, trust will now be the keystone for any system developed for services to learn from untoward incidents, such as the Reporting and Learning System of the National Patient Safety Agency in the UK. This type of trust is complex and is explored in terms of what staff need from management and the potential conflicts that might be involved in developing trust in a healthcare organisation. This paper looks at the societal and emotional context of health care today and at research from other organisations which shows the factors that must be in place to establish trust. It reviews the attributes of leaders who are seen as trustworthy, and looks at how all this can be used to increase the reporting of and learning from error.

Correspondence to: Professor J Firth-Cozens, Special Advisor on Modernisation Postgraduate Medical Education, London Deanery, 20 Guilford Street, London WCIN 4DZ; jfirth-cozens@ londondeanery.ac.uk
T rust has always been an essential part of health care: it underpins the relationship in which clinicians and patients can work cooperatively towards better care. However, organisational trust - that which exists between staff and management-is also a crucial ingredient of quality. Organisational trust has been defined as the extent to which one is willing to ascribe good intentions to, and have confidence in, the words and actions of other people. ${ }^{1}$ This paper explores the effects of trust and the ways in which it can be developed in healthcare organisations to enhance patient safety.

TRUST IS GOOD FOR PATIENTS' HEALTH Trust matters. Over the last two decades occupational psychologists have shown the importance of trust in terms of its beneficial impact on group cohesion, ${ }^{2}$ job satisfaction, ${ }^{3}$ and organisational effectiveness. ${ }^{4}$ Mishra and Morrisey ${ }^{4}$ found that trust was associated with effective decision making, while organisational ineffectiveness was seen by $79 \%$ of participants as the result of staff distrusting their management. Within health services, one of the most important of high quality and, in particular, that it is safe. Good teamwork and job satisfaction both impinge positively upon patient care, and the findings described above-that low levels of organisational trust are likely to affect group indicators of effectiveness is that patient care is cohesion and the satisfaction of staff negatively-show one way in which trust impacts upon the quality of care delivered. ${ }^{5}$ This body of work indicates that trust has always been important for health services to function well. However, over the last few years a more specific requirement for raising trust has emerged.

In its report An Organisation with a Memory, the UK Department of Health spelled out the importance of learning from the errors which have until recently been an unspoken aspect of health care. ${ }^{6}$ In order to learn positively in this way, we need to be sure that those responsible for seeking solutions for things which go wrong-whether locally or nationally-have an accurate idea of the size and shape of the problem. This means they need to feel confident that staff are reporting freely and routinely whenever incidents occur. Recognising the size of the problems enables us to prioritise what matters most, but can also provide us with sufficient data to see the most obvious causes for the lapse in safety-causes which are likely to run right through the system and not just be confined to the sharp end where the individual staff member and patient interact. This process has worked for aviation ${ }^{7}$ and now it is beginning to work for health care. However, if improving patient safety depends at least in part on getting staff to report errors and near misses as a matter of routine, they will need to have high levels of trust in their organisation that this reporting does not have unfair repercussions for them or for the colleague who was reported.

There is now considerable evidence that one of the main deterrents to reporting errors is fear of the consequences ${ }^{8}$ - in particular, a fear of losing one's job. In most organisations an appreciation that incidents will be dealt with openly and fairly appears to be low, so raising trust needs to come high on the agenda of all healthcare systems and will require considerable cultural change. There is also a fear of litigation following such reporting, ${ }^{9}$ and some countries are beginning to tackle this major problem and expense by various legislative means. Litigation might be thought to improve the safety of care in itself, but in reality it seems there is little evidence for this. ${ }^{9}$ Although this area is beyond the scope of this paper, it clearly adds to the complexity of encouraging trust within health care.

\section{TRUST IN THE CONTEXT OF REPORTING ERRORS IN HEALTH CARE}

There are various aspects of trust in the context of reporting errors in health care. Staff have to trust enough to tell the truth about their own errors and sometimes about those they see being made by others. On the other hand, our culture 
proscribes that we are not to "tell tales" on others, in particular our peers and superiors. In order to report the errors of others or of themselves, they need to trust that the matter will be dealt with sensitively, sensibly, and fairly so that an "otherwise good" doctor or nurse-whether themselves or a colleague-will not be judged "guilty until proven innocent". ${ }^{8}$ Staff need to trust that they will not suffer through doing the reporting-that they will not be punished if the error is their own, nor that they will be shunned by colleagues or their actions affect their references when they leave. Finally, they have to trust that recognising and reporting an error will have a better outcome for the patient than doing nothing: that reporting does not take an undue amount of time, and that managers will actually do something to improve patient care as a result of their actions.

Some writers suggest that the protection of one's reputation is a force for being trustworthy. ${ }^{10}$ However, should doctors, for example, protect their reputation as providers of error free care? Or should they increase their trustworthiness by admitting to their errors and near misses and potentially damaging their public reputation?

There are issues for management too. Not only do they need to be trusted to investigate the incident carefully and to treat error fairly, openly, and for the benefit of patient care, they themselves need also to be able to trust that they have the full facts upon which to make decisions. In this sense, the trusting relationship goes both ways. However, in the literature on organisational trust, the act of trusting on the part of managers is almost never considered, perhaps because it comes in the guise of communication or performance management.

Trust within health care is clearly complex but, in creating a cultural change that raises trust, it is necessary to take into account all these aspects of its meaning. The different aspects are summarised in box 1. In encouraging the development of the trust necessary to report errors and learn from them in ways which will improve patient care, all these facets of the trusting relationship need to be systematically taken into account, as well as the context in which those concerned perform their roles.

\section{THE SOCIETAL AND EMOTIONAL CONTEXT}

The level of trust which exists in an organisation will also be affected by the culture and demands of the society and context in which it operates. At the moment we have a drive towards new levels of accountability, and processes such as re-accreditation and various means of external quality assurance are coming into play around the world. ${ }^{11}$ Inevitably this involves a somewhat audit driven culture in our public services. The emphasis on increasing levels of data from healthcare providers does not necessarily result in higher levels of trust from the public. ${ }^{12}$ Nevertheless, these processes are clearly essential in health care, as they are in other industries. What is important in terms of their effects on trust is that those responsible consider the maintenance of trust in their design-for example, that the need for anonymity that underpins the work of some reporting systems is not jeopardised by the wish to name "culprits" expressed by other organisations or by the media. Anecdotal evidence suggests that, if staff are penalised as a result of an information system which is not properly anonymised, the system will fall into disrepute and reporting will drop dramatically.

Another aspect of context which may affect trust comes from the evidence that stress levels are high in health service workers $^{13}$ and the area of error making is a major stressor. ${ }^{14}$ The emotional context of error has been described very forcefully by Leape et al: "... patients and physicians ... live and interact in a culture characterised by anger, blame, guilt,
Box 1 Aspects of trust which need to be developed

Staff

Need to trust management sufficiently in order:

- to tell the truth about their own errors and those of others;

- to be sure they are not seen as telling tales on colleagues but protecting patients;

- that actions to protect patients better will follow their reporting;

- that their reputation will be enhanced by reporting honestly.

\section{Management}

Must be trusted:

- to be open and fair about the handling of error throughout the organisation;

- to investigate the incident with care, integrity, and sensitivity;

- not to harm the one who reports honestly;

- to treat the error maker fairly;

- to use the information well to improve patient care.

Need to trust staff:

- to provide accurate data for their decision and policy making.

fear, frustration and distrust regarding health care errors. The public has responded by escalating the punishment for error. Clinicians and some healthcare organisations generally have responded by suppression, stonewalling and cover-up." ${ }^{15}$

This is the context in which trust has to develop, and ignoring or belittling it will only undermine this process.

\section{THE TRUSTWORTHY ORGANISATION}

There are some general findings about the types of conditions which promote trust within organisations: they need to be less bureaucratic, have higher staff participation in decision making, and more openness of communication. ${ }^{16}$ Carnevale and Wechsler ${ }^{17}$ listed the following as most important: job security, openness of communications, fairness of rewards and punishments, opportunity to participate, and an ethical environment. The most important of these characteristics are discussed below.

\section{Less bureaucracy}

Flatter organisations are usually less bureaucratic and more likely to increase trust ${ }^{16}$ because the distance between the frontline workers and senior management is reduced and communication should be better wherever managers are more visible. As organisations flatten out and decision making moves increasingly to frontline staff, trust becomes more important — that the staff will do their work well, which includes learning from error, and that the management will provide the structures and culture that allow them to do so.

\section{Participation of staff in decision making}

We know from many studies of occupational stress that empowering people-giving them more participation and discretion in how they do their jobs-has a beneficial effect upon stress levels, something that feeds through to better patient care. ${ }^{18} 19$ Recent research has shown that empowering nurses leads to higher levels of organisational trust which in 
turn leads to higher levels of commitment ${ }^{20}$ which has previously been shown to increase organisational effectiveness. It seems that, if you are trusted to do something properly, you are more likely to trust those who trust you and to act more effectively as a result. So how can we empower people? Kanter ${ }^{21}$ considers that this comes about by giving them access to information and resources to do the job, providing support when they need it, and giving them the opportunity to learn and develop.

\section{Openness of communication}

Open communication is the characteristic that appears most frequently in research on developing organisational trust. ${ }^{16}{ }^{22}$ A lack of communication from staff or a growth in rumours is a symptom that trust is low. If managers can maintain open and honest communication when times are bad as well as when they are good, then their staff can gradually learn to do the same. Many innovative companies have used a variety of means of two way communication to reach decisions, design new products, and improve their quality since sharing information can be a source of trust and commitment. ${ }^{23}$

It needs to be remembered too that the words of any communication are considerably less powerful than the gestures, the tone, and the expression of those speaking. It is these non-verbal signs that show staff and patients that their opinion is valued, that their understanding is needed, and that facts are being relayed honestly. To communicate in this way, managers must be visible, must "walk the talk", and appreciate the difficulties of their staff and patients by regularly following the patient pathway through the organisation. $^{24}$

Open and free communication of the good and the bad of health care must be encouraged throughout the process of increasing patient safety, including the analysis of errors themselves. In auditing accidents in refineries, Hirschhorn ${ }^{25}$ has pointed out the importance of considering the multicausal and sociotechnical nature of most accidents and the necessity of looking beyond the most proximate causewhether the individual or the leaking valve. By highlighting only those immediate causes, an accident enquiry can become part of "the same social defence system that helps create the accident in the first place". ${ }^{25}$ In other words, adverse incidents happen more often in a system where people cannot speak openly about their concerns, and this system can be perpetuated by an inquiry which still does not permit this open interaction to allow the discovery of the root causes.

\section{Human resources policies and procedures}

Human resources policies and procedures are also important-for example, through systems of reward and performance appraisal, or of incident analysis, which follows a pathway of procedural justice, where judgment is based on evidence and the process is consistent. ${ }^{26}$ Being seen as open and fair about the treatment of error is essential in terms of the types of error that attract disciplinary procedures. Clearly, some errors which involve reckless behaviour or intentional rule violations are unlikely to be blame free. However, the situation is complex ${ }^{27}$ since not all intentional violations are wrong-sometimes they are even necessary ${ }^{28}$ and, if so, will often be important events to study for safety improvement. While recklessness is a behaviour which clearly attracts discipline, the status of negligence-where you should have known that what you were doing was wrong-may not be so clearcut if the organisation wants to establish a culture based on trust. The Civil Aviation Administration of England (CAA) is unusually lenient in an effort to encourage reporting. They have told air carriers in the UK that "... except to the extent that action is needed in order to ensure safety, and except in such flagrant circumstances as are described above", it expects them to "refrain from disciplinary or punitive action which might inhibit their staff from duly reporting incidents of which they may have knowledge" ${ }^{\prime 2} .{ }^{29}$ What matters most in terms of establishing trust is that the process of decision making in this regard should be clearly communicated, consistent across departments and professions, and seen as fair. Draconian measures have a tendency to lower the safety culture; anectodal evidence suggests that hospitals which have a disciplinary system for medication errors of "three strikes and you're out" find that no nurse ever makes more than two errors!

\section{Culture}

All these factors affect culture and Whitener et $a l^{30}$ suggest that culture will affect trust: those characterised by "inclusiveness, open communications and valuing people will reward managers for collaborating, sharing information, explaining decisions, discussing issues openly and showing concern. Hence, cultures which support these behaviours will also encourage and reward trustworthy behaviour" (page 520). The authors go on to state the importance of initial interactions between employee and manager: expectations need to be engendered on both sides so that any risks of cooperation are minimised. It becomes crucial that the importance placed by the organisation and the teams within it upon safety and error reporting come across unambiguously in staff induction. However, it also needs to be remembered that it is particularly difficult to build trust in a culture of fierce competition for resources and a general climate of social distrust. ${ }^{31}$

\section{Teamworking}

Most health care takes place in teams and teamwork failures have been found to be an important cause of patient errors and litigation claims. ${ }^{32}$ Working together involves some sort of interdependence and this will inevitably involve trust. Good teams-whose roles are clear, where members feel supported, and where good internal and external dialogue takes place-have fewer stressed members and provide better health care. ${ }^{5}$ Without trust, people work together poorly unless they are stringently controlled, ${ }^{33}$ but such control in turn leads to lower levels of trust. This has been demonstrated well in a study of team functioning and medication error where the authors were surprised to find that teams judged as functioning well reported more errors. ${ }^{34}$ Their surprise ended when they interviewed the team leaders and found that the more authoritarian controlling leaders had poorer teams and apparently fewer errors: perhaps only a few brave souls dared to admit to making one.

\section{IS TRUST A PERSONALITY TRAIT?}

There have been some general findings about people's propensity to trust others which are also worth noting-for example, bosses trust their subordinates more than subordinates trust their bosses ${ }^{35}$ - something for all leaders to remember. However, a study of 1279 public service workers found that organisational variables, including those described in the section above, were much better predictors of trust than the characteristics of the staff whose trust was needed. ${ }^{17}$ In a study which compared the trust felt towards one's immediate boss with that felt towards senior management, the propensity of staff to trust, in a dispositional sense, did affect their trust of senior managers but not of their line manager whose actions and the situation they were in became much more important. ${ }^{16}$ Generally, therefore, the trusting personality is not an important aspect of engendering trust unless those to be trusted are remote. This might suggest that encouraging initial error reporting within teams might be an important intermediate step to reporting to any central system in the organisation, even if this is anonymous, 
because it will give individuals real experiences of trust being fulfilled.

There is no doubt, however, that some people are more trusting than others. This is partly the result of their past experiences-what has happened through their lives when they have dared to trust - and partly through having a larger or smaller propensity to take risks. You always have to risk something to put yourself in the vulnerable position of trusting someone, and the extent to which you are willing to do this is probably a combination of personality and experience. The experiences of healthcare staff have frequently been poor in this regard. ${ }^{28}{ }^{36}$ It may seem as though this is not an area which those interested in cultural change have any chance of addressing. In fact, the importance of people's prior experience in trusting or not shows that providing people with consistently different experiences where trust pays off is likely to bring about the desired change: if we once learnt not to do it, we can again learn through happier experiences that it can be done safely. Like so much of what has been said already, this is also going to be part of the role of leaders.

\section{LEADERSHIP, MANAGEMENT, SUPERVISION, AND TRUST}

Good leaders are good for your health ${ }^{37}$-not just the health of staff but also of patients. ${ }^{38}$ The main driver for higher organisational trust is going to come from the actions and attitudes of leaders and managers at every level. ${ }^{8}$ The trustworthiness of individuals has been found to come from three principal characteristics: their ability, their benevolence, and their integrity. ${ }^{39}$

\begin{abstract}
Ability
Ability is an amalgamation of skills and competencies including being able to influence others. For most people this ability will be limited to a single domain such as clinical work or financial management, although trusting someone's ability in less concrete skills may cover a number of domains. These underlying qualities of leadership include being able to set direction, to work collaboratively, be empowering and politically astute, and generally to deliver the service needed. A framework of the abilities of NHS leaders can be found at www.nhsleadershipqualities.nhs.uk.
\end{abstract}

\section{Benevolence}

Benevolence, or the demonstration of concern, is a particularly important characteristic in terms of the trust needed to ensure consistent reporting of error. Recent research on what NHS staff required of their leaders showed that, compared with other types of organisations, they wanted leaders who could do the best for them, what the authors called "the model of leader as servant". ${ }^{40}$ This aspect of leadership is perhaps especially important in health services because of the need for leaders to acknowledge the very real difficulties of clinical care-the stress involved, the lack of resources and, above all, the real anxiety that comes from making errors. Leaders need to show that they understand these difficulties, value their staff, and intend good to them and to their patients. For example, when the media are involved in reporting an untoward incident, the leader has an opportunity to stand by his or her staff, their dedication, the usual excellence of their work, but also the reality that things can go wrong. Another example involves the leader being regularly seen at the front line to experience properly the difficulties and anxieties of both staff and patients, ${ }^{24}$ that they stop expending energy trying to police error punitively, and spend it more on talking face to face, valuing the good and consulting with staff on ways to make it better.

\section{Integrity}

In order to engender the trust of staff, leaders must demonstrate their values and principles by, for example, keeping their word that errors will be treated fairly, taking into account the system and context of the incident. In organisations such as Nissan where quality is seen as the key to effectiveness and profit, integrity is regarded as absolutely essential to its maintenance; once a manager allows something of poor quality to pass through the system because of some expediency, trust is lost. ${ }^{41}$ Demonstrating their integrity can be a real challenge to leaders if they are given two potentially conflicting roles by government-to show greater efficiency while at the same time increasing the quality of care. Unless integrity, benevolence, and competence are shown to healthcare leaders by those who control them, they are going to find it particularly difficult to have the strength to treat their staff in ways which will increase their trust. ${ }^{35}$

As indicated earlier, good supervisory relationships have a very strong positive effect on reported levels of organisational trust. ${ }^{15}{ }^{16}$ While they will include all that has been said about leadership above, the quality of this relationship has been found also to depend on feedback, supervisor confidence and support, fairness of reward and punishment, approachability, openness of communication, and opportunity for participation. One of the most important aspects, in addition to what has been said above, is that approaches must be consistent so that decisions are seen as fair. In terms of errors, this means that incidents must be handled locally in a way that is known to and understood by all staff, and that is unvarying for individuals and professional groups across and between organisations.

\section{RAISING TRUST TO INCREASE REPORTING AND LEARNING}

It is generally agreed in the literature that some types of trust can be intentionally created. This may be more difficult where trust entails the suspension of self-interest in favour of a collective orientation, since "the collective" might be seen as one's colleagues and so reporting them becomes unlikely. This barrier to reporting will occur unless it is constantly demonstrated that the collective duty of health service staff is

Box 2 The National Patient Safety Agency's incident decision tree

The National Patient Safety Agency (NPSA) was set up in 2001 to gather anonymous data about the types and numbers of incidents occurring in the NHS in England and Wales and to develop solutions for the most serious or common of these. To help in the development of the open and fair culture that will be necessary for this, it has developed an incident decision tree based on Reason's culpability model. ${ }^{44}$ Its aim is to help all those involved in an incident to understand the paths which will be taken, depending on the factors involved, such as whether the wrong action was intended or not, whether there was a protocol for that procedure, whether it was followed, whether there was substance abuse or illness involved, or evidence of reckless behaviour. Although error reporting to the NPSA is anonymous, having a decision making route such as this should help to underpin clinicians' confidence in the safety of the reporting system for them and their colleagues; people will not be suspended without good reasons that can be understood by all. Trust should grow as staff see that the process works. ${ }^{45}$ 
Box 3 Strategies for increasing organisational trust

Leadership characteristics

- Ability: to lead; to contain anxiety; to deal with cases fairly.

- Benevolence: showing staff understanding and loyalty; facing difficult times together.

- Integrity: to keep their word; to be honest and consistent.

Organisational structures and processes

- Flatter hierarchies/lower bureaucracy

- Open communication

- Support for teamwork

- Empowering staff

- Appropriate resources, development and support.

- Human resources and risk management policies to support an open and fair culture.

- Rewards for reporting and for showing trustworthy behaviour.

- Experiences of fair results from reporting.

- Actions by managers to remedy problems revealed.

\section{Impact on culture and effectiveness}

- An open and fair culture marked by consistent experiences that trust is well founded.

- A more effective organisation.

to provide better and safer care for patients. So long as this duty is clear and is seen as the primary goal of the organisation and all those within it, then trust in this regard becomes easier to develop: the values and goal of the organisation are truly shared. In addition, it has been shown to be particularly important to get cooperation between doctors and management, a relationship which needs to be driven by a recognition of their interdependence. ${ }^{42}$

The type of trust which is the least difficult to establish is that which comes through the gradual accumulation of direct or indirect knowledge and experience about the other of his or her integrity, benevolence, ability, fair play, etc. ${ }^{43}$ The process of learning by experience that someone's word can be relied upon is most amenable to building the trust necessary for staff to report errors and learn from them. It does, of course, presuppose that the relationships are reasonably stable; it will be much more difficult to build up trust if there is considerable management turnover, particularly as the average time in post of a CEO is often rather brief. However,

\section{Key messages}

- Organisational trust is essential if we are to learn from error and improve patient safety.

- The concept of trust is particularly complex in health care, but these complexities must be addressed and the context of health care appreciated.

- Organisational factors including the characteristics of leaders have been shown to increase trust.

- One untrustworthy act can upset years of hard work in getting trust established. having external anonymous reporting as well as tools such as the incident decision tree developed in the UK by the National Patient Safety Agency (box 2) should help create the necessary consistency even when different individuals are involved in making the decisions. Procedures and processes such as these lead to "institutional based trust" which is more impersonal and tied to formal social structures. This type of trust is important where relationships cross organisational boundaries such as hospitals and professional bodies; here it will be particularly helpful to have ideas of trust shared by both groups using similar processes to consider error and learning.

The strategies for increasing organisational trust discussed or implied in this review are summarised in box 3 .

\section{THE FRAGILITY OF TRUST}

Negative events are more visible than positive ones ${ }^{46}$ and the most important thing to remember is that one false step on the path to trust can upset years of painstaking work. As a result, organisational trust is a fragile thing, broken more easily than it is mended, easily damaged by disconfirming acts. If it is broken, then all the rules about open communication-including the leaders' admission of their own role in causing the upset-need to be adhered to in order to start on the path again. Otherwise, there can be a downward spiral which can paralyse cooperation in the future. ${ }^{43}$

\section{CONCLUSIONS}

The best way to establish trust is to support trustworthiness and trusting, both in leaders and in their staff. This may initially involve recognition and rewarding of trustworthiness in performance management terms in order to provide staff with new good experiences of reporting and learning from error. Avoiding the awakening of shame ${ }^{47}$ and acknowledging the real difficulties of the workplace will be important in this respect. Consistently rewarding the gathering of accurate data will be vital. In this endeavour, the behaviour of leaders is key to demonstrate their integrity and benevolence as well as their ability, and in showing that they are willing to trust their staff. Whitener et $a l^{30}$ suggest that: "By designing organisations in ways that encourage managers to initiate trusting relationships and by rewarding employees for reciprocating, management can establish a foundation for a trusting organisation". From the literature reviewed in this paper, such management practices within health care are likely to enhance organisational effectiveness and improve patient safety.

\section{ACKNOWLEDGEMENT}

The development and writing of this paper was funded by the National Patient Safety Agency, London.

\section{REFERENCES}

1 Cook J, Wall T. New work attitude measures of trust, organisational commitment, and personal need fulfilment. J Occup Psychol 1980;53:39-52.

2 Podsakoff PM, MacKenzie SB, Bommer WH. Transformational leadership behaviours and substitutes for leadership as determinants of employee satisfaction, commitment, trust and organizational citizenship behaviors. J Manage 1996;22:259-98.

3 Driscoll JW. Trust and participation in organisational decision making as predictors of satisfaction. Acad Manage J 1978;21:44-56.

4 Mishra J, Morrisey MA. Trust in employee/employer relationships: a survey of West Michigan managers. Public Personnel Manage 1990;19:443-61.

5 Firth-Cozens J. Cultures for improving patient safety through learning: the role of teamwork. Qual Health Care 2001;10(Suppl 2):i26-31.

6 Department of Health. An organisation with a memory: report of an expert group on learning from adverse events in the NHS. London: HMSO, 2000.

7 Helmreich RL. On error management: lessons from aviation. BMJ 2000;320:781-5.

8 Firth-Cozens J. Learning from error. In: Harrison J, Innes R, Van Zwanenberg T, eds. Regaining trust in health care. Abingdon: Radcliffe Medical Press, 2003. 
9 Brennan T. Patient safety and medical malpractice: a case study. Ann Intern Med 2003;139:267-73.

10 Griffin K. The contribution of studies of source credibility to a theory of interpersonal trust in the communication department. Psychol Bull 1975;68:104-20

11 Klazinga N. Re-engineering trust: the adoption and adaptation of four models for external quality assurance of health care services in western European health care systems. Int J Qual Health Care 2000;12:183-9.

12 O'Neill O. Trust and transparency. A Question of Trust. London: BBC Reith Lectures, 2002.

13 Wall TD, Bolden RI, Borrill CS, et al. Minor psychiatric disorders in NHS trust staff: occupational and gender differences. Br J Psychiatry 1997; 171:519-23.

14 Firth-Cozens J, Greenhalgh J. Doctors' perceptions of the links between stress and lowered clinical care. Soc Sci Med 1997;44:1017-22.

15 Leape LL, Woods DD, Hatlie MJ, et al. Promoting patient safety by preventing medical error. JAMA 1998;280:1444.

16 Clark MC, Payne RL. The nature and structure of workers' trust in management. J Org Behav 1997;18:205-24.

17 Carnevale DG, Wechsler B. Trust in the public sector: individual and organisational determinants. Admin Society 1992;23:471-94.

18 Hatcher S, Laschinger HKS. Staff nurses' perceptions of job empowerment and level of burnout: a test of Kanter's theory of structural power in organizations. Can J Nurs Admin 1996;9:74-94.

19 Firth-Cozens J. Interventions to improve physicians' well-being and patient care. Soc Sci Med 2001;52:215-22.

20 Laschinger HKS, Finegan J, Shamian J, et al. Organizational trust and empowerment in restructured healthcare settings: effects on staff nurse commitment. J Nurs Adm 2000;30:413-25.

21 Kanter RM. Men and women of the corporation, 2nd ed. New York: Basic Books, 1993.

22 Lancaster J. Creating a climate for excellence. J Nurs Adm 1985:16-19.

23 Morgan G. Images of organization. London: Sage, 1997.

24 Schellekens W, Bisognano M. Improving the processes of leadership. Presented at 6th European Forum of Quality Improvement in Health Care, Bologna, 2001.

25 Hirschhorn L. The psychodynamics of safety: a case study of an oil refinery. In: Hirschhorn L, Barnett C, eds. The psychodynamics of organizations. Philadelphia: Temple University Press, 1993:143-64.

26 Creed WED, Miles RE. Trust in organizations. In: Kramer RM, Tyler TR, eds. Trust in organizations: frontiers of theory and research. Thousand Oaks, CA: Sage, 1996:16-38.

27 Marx D. Patient safety and the "just culture": a primer for health care executives. Report in support of Columbia University \& University of Texas Southwestern Medical Center, Dallas, 2001.
28 Firth-Cozens J, Redfern N, Moss F. Confronting errors in patient care, Report commissioned by Department of Health, 2001 (available at www.publichealth.bham.ac.uk/psrp/pdf)

29 Civil Aviation Administration. CAP 382. Civil Aviation Administration of England, 1993.

30 Whitener EM, Brodt SE, Korsgaard MA, et al. Managers as initiators of trust: an exchange relationship framework for understanding managerial trustworthy behavior. Acad Manage Rev 1998;23:513-30.

31 Mechanic $D$. Changing medical organization and the erosion of trust. Milbank Quarterly 1996;74:171-89.

32 Risser DT, Rice MM, Salisbury ML, et al. The potential for improved teamwork to reduce medical errors in the emergency department. Ann Emerg Med 1999;34:373-83.

33 Whitney J. The trust factor. New York: McGraw Hill, 1994:235-49.

34 Edmondson AC. Learning from mistakes is easier said than done: group and organisational influences on the detection and correction of human error. J Appl Behav Sci 1996;32:5-28.

35 Butler JK. Reciprocity of trust between professionals and their secretaries. Psychol Rep 1983;53:411-6.

36 Bosk C. Forgive and remember. Managing medical failure. Chicago: University of Chicago Press, 1979.

37 Firth-Cozens J, Mowbray D. Leadership and the quality of care. Qual Health Care 2001;10(Suppl 2):3-7.

38 Corrigan PW, Lickey SE, Campion BS, et al. Mental health team leadership and consumers' satisfaction and quality of life. Psychiatr Serv 2000;51:781-5.

39 Mayer RC, Davis JH, Schoorman FD. An integrative model of organizational trust. Acad Manage Rev 1995;20:709-34.

40 Alimo-Metcalfe B, Alban-Metcalfe R. Heaven can wait. Health Service J 12 October 2000:26-8.

41 Binney G, Williams C. Leaning into the future: changing the way people change organisations. London: Nicholas Brearley Publishing, 1997:59.

42 Zuckerman HS, Hilberman DW, Andersen RM, et al. Physicians and organizations: strange bedfellows or a marriage made in heaven? Frontiers Health Service Manage 1998;14:3-34.

43 Lane C. Introduction: theories and issues in the study of trust. In: Lane C, Bachmann R, eds. Trust within and between organizations: conceptual issues and empirical applications. Oxford: Oxford University Press, 2000:1-30.

44 Reason J. Managing the risks of organizational accidents. Aldershot: Ashgate, 1997.

45 Firth-Cozens J. The role of the National Patient Safety Agency. Clinical Risk 2003;9:218-21.

46 Slovac P. Perceived risk, trust and democracy. Risk Anal 1993;13:675-82.

47 Davidoff F. Shame: the elephant in the room. Qual Saf Health Care 2002;11:2-3. 